\title{
Hypothalamus-olfactory system crosstalk: orexin A immunostaining in mice
}

\section{Jean Gascuel 1,2,3,4 , Aleth Lemoine ${ }^{2,3,4}$, Caroline Rigault ${ }^{2,3,4}$, Frédérique Datiche ${ }^{2,3,4}$, Alexandre Benani ${ }^{2,3,4}$, Luc Penicaud $^{2,3,4}$ and Laura Lopez-Mascaraque ${ }^{1 *}$}

1 Instituto Cajal, CSIC, Avda del Doctor Arce, Madrid, Spain

${ }^{2}$ CNRS UMR 6265, Centre des Sciences du Goût et de I'Alimentation, Dijon, France

${ }^{3}$ Institut National de la Recherche Agronomique UMR 1324, Centre des Sciences du Goût et de I'Alimentation, Dijon, France

${ }^{4}$ Université de Bourgogne UMR CSGA, Centre des Sciences du Goût et de I'Alimentation, Dijon, France

\section{Edited by:}

Jorge A. Larriva-Sahd, Universidad

Nacional Autónoma de México,

Mexico

\section{Reviewed by:}

Guy Elston, Centre for Cognitive

Neuroscience, Australia

Jorge A. Larriva-Sahd, Universidad

Nacional Autónoma de México,

Mexico

Alfredo Varela-Echavarria, Universidad

Nacional Autónoma de México,

Mexico

\section{*Correspondence:}

Laura Lopez-Mascaraque, Instituto

Cajal, Avda del Doctor Arce 37, 28002

Madrid, Spain.

e-mail:mascaraque@cajal.csic.es
It is well known that olfaction influences food intake, and conversely, that an individual's nutritional status modulates olfactory sensitivity. However, what is still poorly understood is the neuronal correlate of this relationship, as well as the connections between the olfactory bulb and the hypothalamus. The goal of this report is to analyze the relationship between the olfactory bulb and hypothalamus, focusing on orexin A immunostaining, a hypothalamic neuropeptide that is thought to play a role in states of sleep/wakefulness. Interestingly, orexin A has also been described as a food intake stimulator. Such an effect may be due in part to the stimulation of the olfactory bulbar pathway. In rats, orexin positive cells are concentrated strictly in the lateral hypothalamus, while their projections invade nearly the entire brain including the olfactory system. Therefore, orexin appears to be a good candidate to play a pivotal role in connecting olfactory and hypothalamic pathways. So far, orexin has been described in rats, however, there is still a lack of information concerning its expression in the brains of adult and developing mice. In this context, we revisited the orexin A pattern in adult and developing mice using immunohistological methods and confocal microscopy. Besides minor differences, orexin A immunostaining in mice shares many features with those observed in rats. In the olfactory bulb, even though there are few orexin projections, they reach all the different layers of the olfactory bulb. In contrast to the presence of orexin projections in the main olfactory bulb, almost none have been found in the accessory olfactory bulb. The developmental expression of orexin A supports the hypothesis that orexin expression only appears post-natally.

Keywords: orexin A, olfactory system, hypothalamus, food intake behavior, $\mathrm{AOB}, \mathrm{MOB}$, immunocytology

\section{INTRODUCTION}

Everyone at some point in their lives has been astonished by the influence that feeding has on olfactory sensitivity, particularly in

Abbreviations: 3V, third ventricle; Aci, anterior commissure intrabulbar; AHA, anterior hypothal. area; $\mathrm{AOB}$, accessory olfactory bulb; $\mathrm{AOM}$, anterior olfactory nucleus anterior; AOP, anterior olfactory nucleus posterior; APTD, anterior pretectal nucleus dors.; Arc, arcuate nucleus; CCK, cholecystokinin; D3V, dorsal third ventricle; DG, dentate gyrus; DLG, dorsal lateral geniculate; DM, dorso medi hypothal. nu.; DTT, dorsal tenia tecta; E/OV, ependy/olfactory ventricle; $\mathrm{EPl}$, external plexiform layer; fr, fasciculus retroflexus; Gl, glomerular level; GlA, glomerular layer of the accessory olfactory bulb; GnRH, gonadotropin-releasing hormone; GrA, granular cell layer of the accessory olfactory bulb; GrO, granular cell layer; $\mathrm{Hb}$, habenular nucleus; Ipl, internal plexiform layer; LA, lateroant. hypothal. nu.; LH, lateral hypothalamus; LPMR, lat. post. thal. nu.; MD, medio dorsal thalamus nucleus; Me, med amygdala; $\mathrm{ME}$, median eminence; $\mathrm{Mi}$, mitral cell layer; MiA, mitral cell layer of the accessory olfactory bulb; MOB, main olfactory bulb; MPA, med. preoptic area nu.; NPY, neuropeptide Y; OE, olfactory epithelium; OB, olfactory bulb; OPT, olivary pretectal nucleus; opt, optical nerve; PaAP, pa. anterior parvicell. Pt. pc, post commissure; PF, para fascicular thalamus nucleus; Pir, piriform cortex; PLCo, postlat cx amygdale nu.; PMV, premammill. nu. ventral; Po, post. thal. nu.; PV, paraventricular thalamic nucleus; PVP, paraventricular thalamic nucleus post; SCh, suprachiasmatic nu.; SCO, sub commissural organ; SSS, sensory specific satiety; TS, triangular septal nucleus; VIP, vasoactive intestinal peptide; VLG, ventral lateral geniculate; VMH, the perception of food-associated odorants. This suggests that one of the first ways in which the brain regulates food intake behavior is by modulating the perception of the food odorant itself. Indeed, such change in sensory perception has been defined as alliesthesia (Cabanac and Duclaux, 1973; Duclaux et al., 1973) and sensory specific satiety (SSS; Yeomans, 2006). At the most peripheral level - the olfactory epithelium (OE) - many neuropeptides and metabolic hormones such as Gonadotropin-Releasing Hormone (GnRH), Neuronal Peptide Y (NPY), leptin, adiponectin, and orexins are thought to modulate the sensitivity of olfactory sensory neurons in different species. For instance, in lower vertebrates, $\mathrm{LHRH} / \mathrm{GnRH}$, released by the nervus terminalis (NT) at the OE level (Wirsig-Wiechmann, 1993; Oka, 1997), modulates olfactory neuronal sensitivity (Kawai et al., 2009) reducing evoked responses to food odorant cues during the reproductive period in Axolotl. This allows the olfactory system to be available predominantly for odorants involved in mating (Mousley et al., 2006). In contrast, NPY, an orexigenic neuropeptide, is also released producing

ventral hypothalamic nu.; VPL, ventro postero lateral; VPM, ventro postero med. thal.; VTT, ventral tenia tecta. 
an inverse effect in the OE, i.e., causing an increase in sensitivity to food odorants (Mousley et al., 2006). In mammals, hormonal mechanisms have also been shown to modulate the sensitivity of the olfactory system. Leptin - a hormone produced by adipocytes in proportion to the fat content, and involved in modulation of the neuronal network linked to energy balance (Friedman, 2002; Pinto et al., 2004) - is present in the OE and has a modulatory effect on olfactory sensory neurons (Savigner et al., 2009). Similarly, adiponectin receptors 1 (receptor for adiponectin, a hormone involved in glucose and lipid metabolism) are expressed by mature sensory neurons (Hass et al., 2008), suggesting that this peptide is also able to modulate olfactory responses.

At the central level, many hormones and neuropeptides such as vasoactive intestinal peptide (VIP, Garcia-Llanes et al., 2003), cholecystokinin (CCK, Tanganelli et al., 2001), NPY (Matsutani et al., 1988), LHRH/GnRH (Apelbaum et al., 2005), and insulin (Fadool et al., 2011) may modulate olfactory processing. However, besides such hormonal mechanisms, a body of data (Doucette et al., 2007; Doucette and Restrepo, 2008; Fletcher and Chen, 2010) suggests the existence of a neuronal centrifugal modulation of olfactory bulb (OB) activity in different tasks, including the modulation of olfactory sensitivity toward food odorants (Pager et al., 1972; Pager, 1978; Royet et al., 1983). Different pathways (Figure 1), which are known to connect hypothalamic nuclei with olfactory centers, could be the neuroanatomical substrates accounting for the observations reported by Pager (1978). Among these, the "orexin/hcrt neurones" appear to be a likely candidate. Indeed, orexin/hypocretin (hcrt), a neuropeptide involved in sleep/wake regulation (Sakurai et al., 1998, 2010; Sakurai and Mieda, 2011), is also involved in feeding behavior (Horvath and Gao, 2005). Many studies have demonstrated that it could act by modulating olfactory sensitivity according to satiety (Aimé et al., 2007; Julliard et al., 2007; Prud'homme et al., 2009, for review: Palouzier-Paulignan et al., 2012). The cytological, connectional (Hahn and Swanson, 2010, 2012), immunohistological, and molecular (Peyron et al., 1998; Sakurai et al., 2005; Swanson et al., 2005) characterization of the lateral hypothalamus (LH) has already been performed. These studies suggest the existence of a functional loop between olfactory centers and the hypothalamus, which could explain the modulation of olfaction depending on energy balance. Unfortunately, inputs that project to orexin neurons have been shown in mice (Sakurai et al., 2005), while the LH orexin neuron projections to the $\mathrm{OB}$ have been shown in rats (Peyron et al., 1998; Nambu et al., 1999). Showing the existence of synaptic output from $\mathrm{LH}$ orexin neurons to the $\mathrm{OB}$ is a prerequisite to validate the reality of this loop in mice. Owing to the fact that the orexin immunostaining pattern presents variations amongst rodents, for instance between rats and hamsters (Nixon and Smale, 2007), the first preliminary step toward the validation of the putative loop between the $\mathrm{LH}$ and the OB was to validate data in mice obtained previously in rats (Peyron et al., 1998; Nambu et al., 1999). The aim of this study being established, future studies will address the question of connectivity through a trans-synaptic tracer experiment in order to draw the exact circuitry between $\mathrm{OB}$ and hypothalamus.
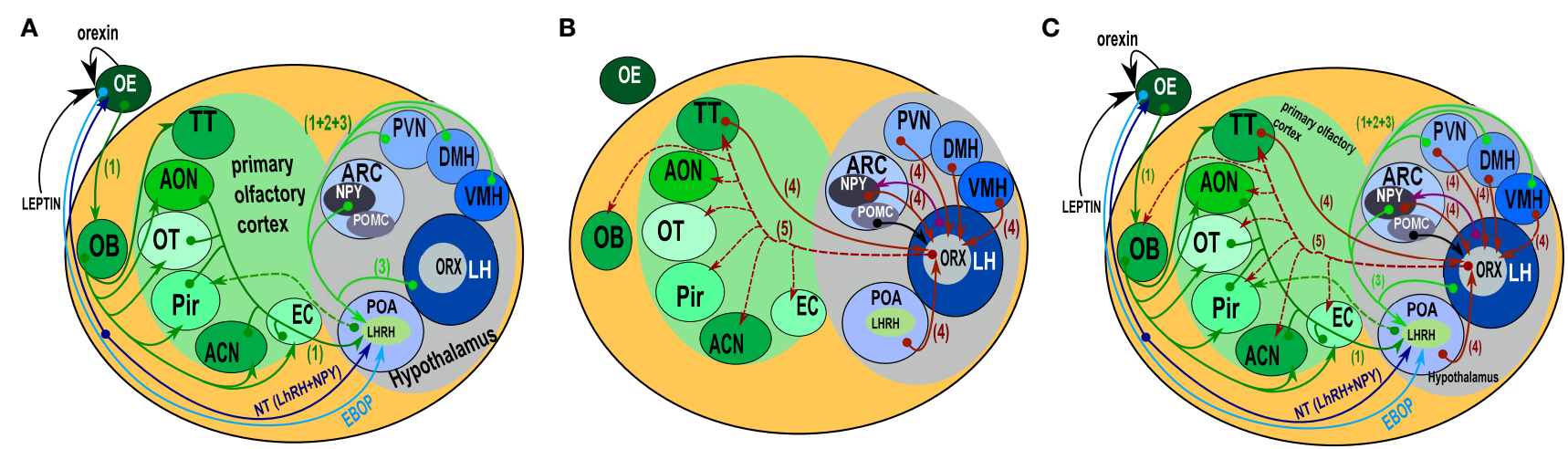

FIGURE 1 | Schematic representation of the "connectome" between the olfactory system and the hypothalamus. (A) Paracrine, extrabulbar connection, and afferents to $\mathrm{LHRH} / \mathrm{GnRH}$ hypothalamic neurons. Orexin and leptin could modulate olfactory neuron sensitivity by paracrine action. The EBOP (Extra Bulbar Olfactory Pathway) is made up of sensory neurons that project directly to the POA in the hypothalamus. However, this pathway has only been identified in lower vertebrates. In contrast, the Nervus Terminalis is known in mammals and humans. This complex structure, which projects both to the olfactory epithelium and the POA, is thought to play a bidirectional modulatory role. $\mathrm{LHRH} / \mathrm{GnRH}$ neurons get afferents from nearly all the areas of the olfactory system (including the OB), and from the most important hypothalamic structures involved in the regulation of food intake behavior (1, 2). However, no direct output onto olfactory structures has been evidenced. (B) Afferents onto orexin neurons (4). Orexin neurons received input from nearly all of the hypothalamic areas. Interestingly, they also received input from the Tenia Tecta (TT) of the olfactory cortex. From the arcuate nucleus, both POMC and NPY (6) neurons project onto orexin neurons. Both the input and output (Peyron et al., 1998) of orexin neurons are represented. Output data are only from rats, but they provided evidence of a putative output from orexin neurons onto the olfactory structures and input from the TT of the olfactory cortex onto orexin neurons. (C) This synthetic representation, even though incomplete, reveals the complexity of the putative interactions between olfaction and hypothalamic areas. (1 =Yoon et al., 2005; 2 = Boehm et al., 2005; 3, 6=Yoshida et al., 2006; $4=$ Sakurai et al., 2005; $5=$ Peyron et al., 1998; $6=$ Elias et al., 1998). ACN, amygdaloïd cortical nucleus; $A O N$, anterior olfactory nucleus; $A R C$, arcuate nucleus; $\mathrm{DMH}$, dorso medial nucleus of the hypothalamus; EBOP, extra bulbar olfactory pathway; EC, entorhinal cortex; LH, lateral hypothalamus; NT, nervus terminalis; OB, olfactory bulb; OE, olfactory epithelium; OT, olfactory tubercle; Pir, cortex piriform; POA, preoptic area; PVN, paraventricular nucleus of the hypothalamus; $\mathrm{TT}$, tenia tecta; $\mathrm{VMH}$, ventro medial nucleus of the hypothalamus. 


\section{MATERIALS AND METHODS ANIMALS}

C57 mice were raised at the Cajal Institute mouse-breeding facility. All procedures followed the guidelines for animal care of the European Community Council (86/609/CEE), and were approved by the Bioethical Committee of the Spanish National Research Council (CSIC). The animals were kept under a constant 12-12 h dark-light cycle (light on at 07:00am). The day the vaginal plug was detected was designated as embryonic day 0 (E0). The mice were killed by hypothermia (embryos and P3) or with i.p. equithesin at a sub-lethal dose ( $3 \mathrm{~mL} / \mathrm{kg}$ body weight; from P3 to adult) systematically at the same time of the diurnal cycle $(04: 00 \mathrm{pm})$.

\section{IMMUNOHISTOCHEMISTRY}

After anesthesia, the mice were transcardially perfused with $4 \%$ paraformaldehyde $(\mathrm{PF})$ in $0.1 \mathrm{M}$ phosphate buffer (PB, $\mathrm{pH}$ 7.2). The brains were then post-fixed in $\mathrm{PF}$ for $2 \mathrm{~h}$ at $4^{\circ} \mathrm{C}$, and coronal vibratome sections were obtained at $70 \mu \mathrm{m}$. One out of three sections was used for immunocytochemistry. Unspecific binding of antibodies was blocked by three washes in NGS $10 \%$ in Tris buffered saline with $5 \%$ Tween (TBS-T), followed by overnight incubation using primary rabbit anti-orexin A (Millipore AB3098; Sakurai et al., 1998) and diluted to 1:1000 in the buffer. Antibody binding was detected with the secondary antibody goat Anti-rabbit Alexa 488 (Invitrogen A11001) diluted to 1:700 during $2 \mathrm{~h}$ at room temperature. Sections were then washed three times in TBS-T. Nuclei were counterstained with Hoechst $(1 \mu \mathrm{g} / \mathrm{ml}$, Sigma-Aldrich Co.). The control consisted of substituting the primary antibody by an orexin $B$ antibody, followed by the same immunohistological protocol just described.

\section{MICROSCOPY AND IMAGE PROCESSING}

Optical sections were acquired using a Leica SP5 confocal microscope, 10× objectives HPC PL Apo CS dry UV, at a resolution of $1024 \times 1024$, without zoom magnification. The voxel size was $1.51 \times 1.51 \times 5.32$. Whole coronal sections of the brains were reconstructed by doing $\mathrm{XY}$ mosaics using Leica software. For each $\mathrm{XY}$ position, six to seven optical sections were acquired in Z. Projections were made with a "Max intensity" algorithm using FIJI (an ImageJ plug-in). Relative quantification of orexin fibers was determined after thresholding the image in order to differentiate the neurite profile from the background. The measurements give values in percentage of surface area, thus expressing the density of orexin fibers per unit of area.

\section{TISSUE DISSECTION AND RNA EXTRACTION AND PROCESSING}

After decapitation, embryo (E17) and newborn (P3) brains were rapidly dissected on ice. For adult males and 11-day-old mice (P11) the hypothalamus and cerebellum were quickly microdissected on ice systematically at the same time of the diurnal cycle (between 02:00 and 04:00pm). Liver tissue was also isolated from each animal. All of the collected tissues were immediately frozen in liquid nitrogen and stored at $-80^{\circ} \mathrm{C}$. Total RNA was extracted using the RNeasy Mini Kit (Qiagen). Possible DNA contaminants in the RNA preparation were eliminated by treatment with DNAse I (Qiagen). RNA quality was assessed with the Experion electrophoresis system (Bio-Rad) and the Experion RNA StdSens
Analysis Kit (Bio-Rad). Total RNA concentration was determined using the Nanodrop spectrophotometer (Thermo Scientific).

\section{REAL-TIME PCR ANALYSIS}

Reverse transcription was performed with $500 \mathrm{ng}$ of total RNAs, using the High-Capacity RNA-to-cDNA Master Mix (Applied Biosystem). For qPCR, the Fast SYBR Green Master Mix (Applied Biosystems) was used. Each reaction contained $1 \mu \mathrm{l}$ of cDNA diluted $1: 10$ and $200 \mathrm{nM}$ of gene specific intron-spanning primers. The sequences of the primers used for prepro-orexin (Ppox) amplification were 5'-GGCACCATGAACTTTCCTTC$3^{\prime}$ and $5^{\prime}$-GACAGCAGTCGGGCAGAG-3'. TATA box binding protein (Tbp) RNA expression was used as an endogenous control. The sequences of the primers were $5^{\prime}$ GGGAGAATCATGGACCAGAA- $3^{\prime}$ and $5^{\prime}$-CCGTAAGGCATCAT TGGACT- $3^{\prime}$. Real-time PCR reactions were performed on a StepOne Plus thermocycler (Applied Biosystems). PCR conditions were $20 \mathrm{~s}$ at $95^{\circ} \mathrm{C}$, followed by 40 cycles of $3 \mathrm{~s}$ at $95^{\circ} \mathrm{C}$ and $30 \mathrm{~s}$ at $60^{\circ} \mathrm{C}$. Relative quantitation of gene expression (RQ) was based on the $\Delta \Delta C_{\mathrm{t}}$ method.

\section{RESULTS}

\section{OREXIN IN ADULT MICE}

We analyzed orexin A staining all along the antero-posterior axis of the mouse brains by immunohistochemistry. We selected confocal coronal sections, from the $\mathrm{OB}$ to the cerebellum, to perform a semi-quantitative evaluation of orexin A staining (Table 1), and compared the results with rat orexin staining (Peyron et al., 1998). For each brain area reported in Table 1, we quantified the percentage of orexin fibers (see "Materials and Methods"). Our data revealed that in mice, the orexin $\mathrm{A}$ immunostaining was as follows:(i) the localization of orexin A neuronal cell bodies in the LH (ii) a wide distribution of orexin A fibers in all brain areas except the cerebellum and caudate putamen, (iii) a strong presence of orexin A fibers in the thalamus and the hypothalamus. Therefore, the mouse orexin A pattern is similar to that in rats, even though there are some minor differences.

In the mouse, the thalamic area appeared to be heavily orexin A labeled (Figure 2) at the level of the parafascicular thalamic nucleus (PF; Figure 2C), the paraventricular nuclei (PV; Figures $\mathbf{2 A}$ and $\mathbf{3 B}$ ), the subcommissural organ (SCO; Figure 2B), the central medial, and mediodorsal (MD) thalamic nuclei (Figure 2A). Nevertheless, the immunostaining was not homogeneous throughout the whole thalamus. It appeared faintly stained in epithalamic areas: such as the lateral and medial habenular nucleus ( $\mathrm{Hb}$, Figure $\mathbf{2 A}$ ), the olivary pretectal nucleus (OPT, Figure 2C) and the antero-pretectal-dorsal nucleus (APTD, Figure 2C). At the geniculate nucleus level, there was no orexin $\mathrm{A}$ in the dorso-lateral geniculate nucleus (DLG; Figure 2D), while the ventral lateral geniculate nucleus (VLG) was strongly stained (Figure 2D). There was almost no staining in the ventro lateral thalamus, the ventro-postero-lateral (VPL) and ventro-postero-medial thalamic nuclei (VPM; Figure 2D).

At hippocampus level, the staining was discrete and mostly located in CA1 and CA2. CA3 was consistently less stained than CA1 or CA2 (Figure 2E). The dentate gyrus was poorly labeled by orexin A staining (Figures $2 \mathrm{~A}-\mathrm{C}$ ). The triangular septal nucleus 
Table 1 | Semi-quantitative estimation of the density of presence in different brain areas.

\begin{tabular}{|c|c|c|}
\hline \multicolumn{3}{|c|}{ AMYGDALE } \\
\hline AHiAL & Amygdalohippocampal area, anterolateral part & $0.01<X<0.49$ \\
\hline BLA & Basolateral amygdaloid nucleus, anterior part & $0.01<X<0.49$ \\
\hline BLP & Basolateral amygdaloid nucleus, posterior part & $0.01<X<0.49$ \\
\hline BLV & Basolateral amygdaloid nucleus, ventral part & $0.01<X<0.49$ \\
\hline BMA & Basomedial amygdaloid nucleus, anterior part & $0.49<X<0.99$ \\
\hline BMP & Basomedial amygdaloid nucleus, posterior part & $0.01<X<0.49$ \\
\hline ASt & Amygdalostriatal transition area & $0.01<X<0.49$ \\
\hline $\mathrm{CeC}$ & Central amygdaloid nucleus, capsular part & $0.49<X<0.99$ \\
\hline CeL & Central amygdaloid nucleus, lateral division & $0.49<X<0.99$ \\
\hline LaVL & Lateral amygdaloid nucleus, ventrolateral part & $0.01<X<0.49$ \\
\hline LaVM & Lateral amygdaloid nucleus, ventromedial part & $0.01<X<0.49$ \\
\hline MeAD & Medial amygdaloid nucleus, anterodorsal & $x>1$ \\
\hline MeAV & Medial amygdaloid nucleus, anteroventral part & $x>1$ \\
\hline MePD & Medial amygdaloid nucleus, posterodorsal part & $0.01<X<0.49$ \\
\hline MePV & Medial amygdaloid nucleus, posteroventral part & $0.01<X<0.49$ \\
\hline PLCo & Posterolateral cortical amygdaloid area & $0.01<X<0.49$ \\
\hline PMCo & Posteromedial cortical amygdaloid area & $0.01<X<0.49$ \\
\hline \multicolumn{3}{|c|}{ BASAL GANGLIA } \\
\hline MS & Medial septal nucleus & $0.01<X<0.49$ \\
\hline \multicolumn{3}{|c|}{ CORTEX } \\
\hline AIP & Agranular insular cortex, posterior part & $0.01<X<0.49$ \\
\hline Au1 & Primary auditory cortex & $0.01<X<0.49$ \\
\hline AuD & Secondary auditory cortex, dorsal area & $0.01<X<0.49$ \\
\hline AuV & Secondary auditory cortex, ventral area & $0.01<X<0.49$ \\
\hline Cg1 & Cingulate cortex, area 1 & $0.49<X<0.99$ \\
\hline Cg2 & Cingulate cortex, area 2 & $0.49<X<0.99$ \\
\hline CXA & Cortex-amygdala transition zone & $0.49<X<0.99$ \\
\hline DEn & Dorsal endopiriform claustrum & $0.01<X<0.49$ \\
\hline DI & Dysgranular insular cortex & $0.01<X<0.49$ \\
\hline DIEnt & Dorsal intermediate entorhinal cortex & $0.01<X<0.49$ \\
\hline DLEnt & Dorsolateral entorhinal cortex & $0.01<X<0.49$ \\
\hline DP & Dorsal peduncular cortex & $0.49<X<0.99$ \\
\hline Ect & Ectorhinal cortex & $0.01<X<0.49$ \\
\hline LO & Lat orbital cortex & $0.49<X<0.99$ \\
\hline $\mathrm{MO}$ & Medial orbital cortex & $0.49<X<0.99$ \\
\hline $\mathrm{Ml}$ & Primary motor cortex & $0.01<X<0.49$ \\
\hline M2 & Secondary motor cortex & $0.01<X<0.49$ \\
\hline PRh & Perirhinal cortex & $0.01<X<0.49$ \\
\hline PRh & Perirhinal cortex & $0.01<X<0.49$ \\
\hline S1BF & Primary somatosensory cortex, barrel field & $0.01<X<0.49$ \\
\hline S1DZ & Primary somatosensory cortex, dysgranular zone & $0.01<X<0.49$ \\
\hline S1FL & Primary somatosensory cortex, forelimb region & $0.01<X<0.49$ \\
\hline $\mathrm{S} 1 \mathrm{HL}$ & Primary somatosensory cortex, hindlimb region & $0.01<X<0.49$ \\
\hline S1ULp & Primary somatosensory cortex, upper lip region & $0.01<X<0.49$ \\
\hline S2 & Secondary somatosensory cortex & $0.01<X<0.49$ \\
\hline TeA & Temporal association cortex & $0.01<X<0.49$ \\
\hline V2L & Secondary visual cortex, lateral area & $0.01<X<0.49$ \\
\hline VEn & Ventral endopiriform claustrum & $0.49<X<0.99$ \\
\hline VO & Ventral orbital cortex & $0.49<X<0.99$ \\
\hline \multicolumn{3}{|c|}{ HYPOCAMPE } \\
\hline CA1 & Field ca1 of the hippocampus & $0.01<X<0.49$ \\
\hline CA2 & Field ca2 of the hippocampus & $0.01<X<0.49$ \\
\hline CA3 & Field ca3 of the hippocampus & $X=0$ \\
\hline DG & Dentate gyrus & $X=0$ \\
\hline
\end{tabular}

(Continued)

\begin{tabular}{|c|c|c|}
\hline \multicolumn{3}{|c|}{ HYPOTHALAMUS } \\
\hline $\mathrm{AHA}$ & Anterior hypothalamic area, posterior part & $x>1$ \\
\hline Arc & Arcuate hypothalamic nucleus & $x>1$ \\
\hline DA & Dorsal hypothalamic area & $x>1$ \\
\hline DM & Dorsomedial hypothalamic nucleus & $x>1$ \\
\hline LA & Lateroanterior hypothalamic nucleus & $0.49<X<0.95$ \\
\hline $\mathrm{LH}$ & Lateral hypothalamic area & $x>1$ \\
\hline MPA & Medial preoptic area & $x>1$ \\
\hline $\mathrm{PaAP}$ & $\begin{array}{l}\text { Paraventricular hypothalamic nucleus, } \\
\text { anterior parvic }\end{array}$ & $x>1$ \\
\hline PaLM & $\begin{array}{l}\text { Paraventricular hypothalamic nucleus, lateral } \\
\text { magnoce }\end{array}$ & $x>1$ \\
\hline $\mathrm{PaV}$ & $\begin{array}{l}\text { Paraventricular hypothalamic nucleus, ventral } \\
\text { part }\end{array}$ & $x>1$ \\
\hline $\mathrm{Pe}$ & Periventricular hypothalamic nucleus & $0.01<X<0.49$ \\
\hline $\mathrm{PH}$ & Posterior hypothalamic nucleus & $0.01<X<0.49$ \\
\hline PMV & Premammillary nucleus, ventral part & $x>1$ \\
\hline $\mathrm{Te}$ & Terete hypothalamic nucleus & $0.49<X<0.99$ \\
\hline VMH & Ventromedial hypothalamic nucleus & $x>1$ \\
\hline $\mathrm{SCH}$ & Supra chiasmatic nucleus & $X=0$ \\
\hline \multicolumn{3}{|c|}{ MIDBRAIN/HINDBRAIN } \\
\hline APTD & Anterior pretectal nucleus, dorsal part & $0.49<X<0.99$ \\
\hline $\ln C$ & Interstitial nucleus of Cajal & $x>1$ \\
\hline IP & Interpeduncular nucleus & $x>1$ \\
\hline IF & Interfascicular nuclei & $x>1$ \\
\hline SN & Subs. Nigra & $0.49<X<0.99$ \\
\hline \multicolumn{3}{|c|}{ OLFACTORY SYSTEM } \\
\hline $\mathrm{AOB}$ & Accessory olfactory bulb & $0.01<X<0.49$ \\
\hline AON & Anterior olfactory nuclei & $0.49<X<0.99$ \\
\hline TT & Dorsal tenia tecta & $0.49<X<0.99$ \\
\hline CoPyr & Pyriform cortex & $0.49<X<0.99$ \\
\hline MOB & Main olfactory bulb & $0.01<X<0.49$ \\
\hline \multicolumn{3}{|c|}{ SEPTUM } \\
\hline Ts & Triangular septum nuclei & $0.49<X<0.99$ \\
\hline \multicolumn{3}{|c|}{ STRIATUM } \\
\hline AA & Anterior amygdaloid area & $0.49<X<0.99$ \\
\hline $\mathrm{ACo}$ & Anterior cortical amygdaloid area & $0.49<X<0.99$ \\
\hline $\mathrm{CPu}$ & Caudate putamen (striatum) & $0.01<X<0.49$ \\
\hline $\mathrm{ICjM}$ & Island of Calleja, major island & $0.49<X<0.99$ \\
\hline LSD & Lateral septal nucleus, dorsal part & $0.49<X<0.99$ \\
\hline LSI & Lateral septal nucleus, intermediate part & $0.49<X<0.99$ \\
\hline \multicolumn{3}{|c|}{ TECTUM } \\
\hline DpG & Deep gray layer of the superior colliculus & \\
\hline DpWh & Deep white layer of the superior colliculus & \\
\hline \multicolumn{3}{|c|}{ THALAMUS } \\
\hline$A D$ & Anterodorsal thalamic nucleus & $X=0$ \\
\hline APTD & Anterior Pretectal nucleus, Dorsal & $X=0$ \\
\hline $\mathrm{CM}$ & Central medial thalamic nucleus & $x>1$ \\
\hline DLG & Dorsal lateral geniculate nuclei & $X=0$ \\
\hline Gus & Gustatory thalamus nuclei & $0.01<X<0.49$ \\
\hline IGL & Intra geniculate leaf & $x>1$ \\
\hline LDDM & $\begin{array}{l}\text { Laterodorsal thalamic nucleus, dorsomedial } \\
\text { part }\end{array}$ & $0.01<X<0.49$ \\
\hline LDVL & $\begin{array}{l}\text { Laterodorsal thalamic nucleus, ventrolateral } \\
\text { part }\end{array}$ & $0.01<X<0.49$ \\
\hline
\end{tabular}

(Continued) 


\section{Table 1 | Continued}

\begin{tabular}{lll}
\hline LHbL & Lateral habenular nucleus, lateral part & $X=0$ \\
LHbM & Lateral habenular nucleus, medial part & $X=0$ \\
MD & Mediodorsal thalamic nucleus & $X>1$ \\
MDM & Mediodorsal thalamic nucleus, medial part & $0.01<X<0.49$ \\
OPT & Olivary pretectal nucleus & $X=0$ \\
PAG & Thalamus gray & $X>1$ \\
PC & Paracentral thalamic nucleus & $X>1$ \\
PF & Parafacicular thalamus nuclei & $X>1$ \\
Po & Post thalamus nuclei & $0.01<X<0.49$ \\
PT & Paratenial thalamic nucleus & $X>1$ \\
PV & Paraventricular thalamic nucleus & $X>1$ \\
PVA & Paraventricular thalamic nucleus, anterior & $X>1$ \\
& part & \\
PVP & Paraventricular thalamic nucleus, posterior & $X>1$ \\
& part & $X>1$ \\
Re & Reuniens thalamic nucleus & $X>1$ \\
Sm & Stria medullaris & $0.49<X<0.99$ \\
VLGMC & Vent lat genic magn & $0.49<X<0.99$ \\
VLGPC & Vent lat genic magn & $X=0$ \\
VL & Ventro lateral thalamus & $X=0$ \\
VPL & Ventro-postero-lateral thalamus & $X=0$ \\
VPM & Ventro postero medial thalamus & $0.49<X<0.99$ \\
SCO & Sub commissural organ & $0.49<X<0.99$ \\
SI & Substancia inominata & $X>1$ \\
CP & Cereb pedunc basal pt &
\end{tabular}

(TS) area of the septum appeared to be stained consistently (Figure 2F).

The orexin A fibers were most abundant in the hypothalamus (Figure 3). The whole paraventricular area appeared to be very rich in orexin A fibers. In the anterior part of the hypothalamus (Figure 3A) the following parts were densely stained: the latero anterior hypothalamic nucleus (AHA); the medial preoptic area (MPA); the paraventricular anterior parvicellular part (PaAP) of the hypothalamic nucleus and the anterior LH. In contrast, no labeling was observed in both suprachiasmatic (SCh; Figure 3A) and supraoptic nuclei (not shown). In the LH, there is the orexin A neuron cell body population (Figure 3B). The dorso medial hypothalamus (DM), the ventral medial hypothalamus nucleus (VMH), and the arcuate nucleus (Arc) were densely stained. Caudally, the $\mathrm{LH}$, the $\mathrm{VMH}$, and the arcuate nucleus were stained (Figure 3C). Figures 3D,E present magnifications of the orexin A neuronal cell bodies and orexin A fibers respectively.

In the $\mathbf{O B}$, there were fewer orexin A fibers than in the hypothalamic or thalamic areas; nonetheless they appeared to be present (Figure 4). According to the literature, the mitral layer in rats contains no orexin A fibers (Peyron et al., 1998). By contrast, orexin A fibers were seen in all the different layers of the main olfactory bulb (MOB), including the glomerular and the mitral cell layers (Figure 4A). Unlike the MOB, the accessory olfactory bulb (AOB) seemed to be devoid of orexin A fibers except in the granular cell layer (Figure 4B).

In the olfactory cortex, the density of orexin A appeared to lie between the MOB and the hypothalamus (Figure 5). Relatively dense staining was observed in the anterior olfactory nucleus
(AOM and $\mathrm{AOP}$ ), in the ventral and dorsal tenia tecta (VTT and DTT; Figure 5B). The same occurs in the piriform (Pir) and the entorhinal cortices (Figure 5A). We also investigated the amygdala, which is not olfactory per se, but is strongly connected to the olfactory system (Figure 5A). In areas of the amygdala, the staining was very dense as for instance in the medial amygdaloid nucleus (Me).

\section{DEVELOPMENTAL EXPRESSION OF OREXIN}

We also analyzed orexin A immunolocalization at different developmental stages, ranging from E11 to P11. We found the first evidence of the clear expression of orexin A at P11 (Figures 6A,B). At this stage, cell bodies in the LH appeared clearly stained even though just a few fibers were manifest. Orexin A and B are produced from a common polypeptide precursor, prepro-orexin (Ppox) by proteolytic processing (de Lecea et al., 1998; Sakurai et al., 1998). In order to confirm immunocytochemical data, we performed a real-time PCR analysis using Ppox primers (Figure 7). We showed that the level of expression of Ppox is barely detectable at $\mathrm{E} 17(\mathrm{RQ}=1.19)$ and very low at $\mathrm{P} 3(\mathrm{RQ}=4.17)$. In contrast, a strong increase in the level of expression was observed at P11 $(\mathrm{RQ}=344.4)$ and in the adult stage $(\mathrm{RQ}=1944.11)$. Ppox mRNA was undetectable in the liver at any developmental stage and in cerebellum of P11 and adult (data not shown).

\section{DISCUSSION}

Our data showed orexin A immunostaining in mice when compared with that described in rats. Orexin was found in nearly all brain areas except in the caudate putamen and cerebellum, with a strong expression in thalamus and hypothalamus. Moreover, while in the MOB was detected a sparse orexin A labeling throughout the different layers, almost no presence was detected in the AOB. The developmental expression of orexin A supports the hypothesis that orexin expression only appears post-natally.

\section{ADULT OREXIN PATTERNS}

Even though convergent data revealed a link between olfactory perception and satiety (Pager et al., 1972; Pager, 1978; Yeomans, 2006), the neuroanatomical basis for this relationship and the exact connectome between olfaction centers and the hypothalamus is poorly known. Figure 1 summarizes the neuroanatomical connection between olfactory centers and the hypothalamus. From the peripheral olfactory system to the hypothalamus, two direct connections are described that do not synapse in the OB (Figure 1A). The first, the extra bulbar olfactory pathway (EBOP), is mainly known in lower vertebrates (fish, amphibians; Eisthen and Polese, 2006) and is composed of sensory neurons located in the OE, which project onto the preoptic area (POA) of the hypothalamus. The second, the NT, is a complex structure identified in many vertebrates including mammals and humans (Johnston, 1914; Fuller and Burger, 1990; Wirsig-Wiechmann, 1993, 1997). It is composed of ganglion(s) in which the neuronal cell bodies are located (Eisthen and Polese, 2006; Mousley et al., 2006; Kawai et al., 2009) that send branches towards both the $\mathrm{OE}$ and anterior POA of the hypothalamus. Due to its complex structure, the NT is not very well known. This is regrettable because the NT is certainly one of the systems most likely to be involved in the neuromodulation of 

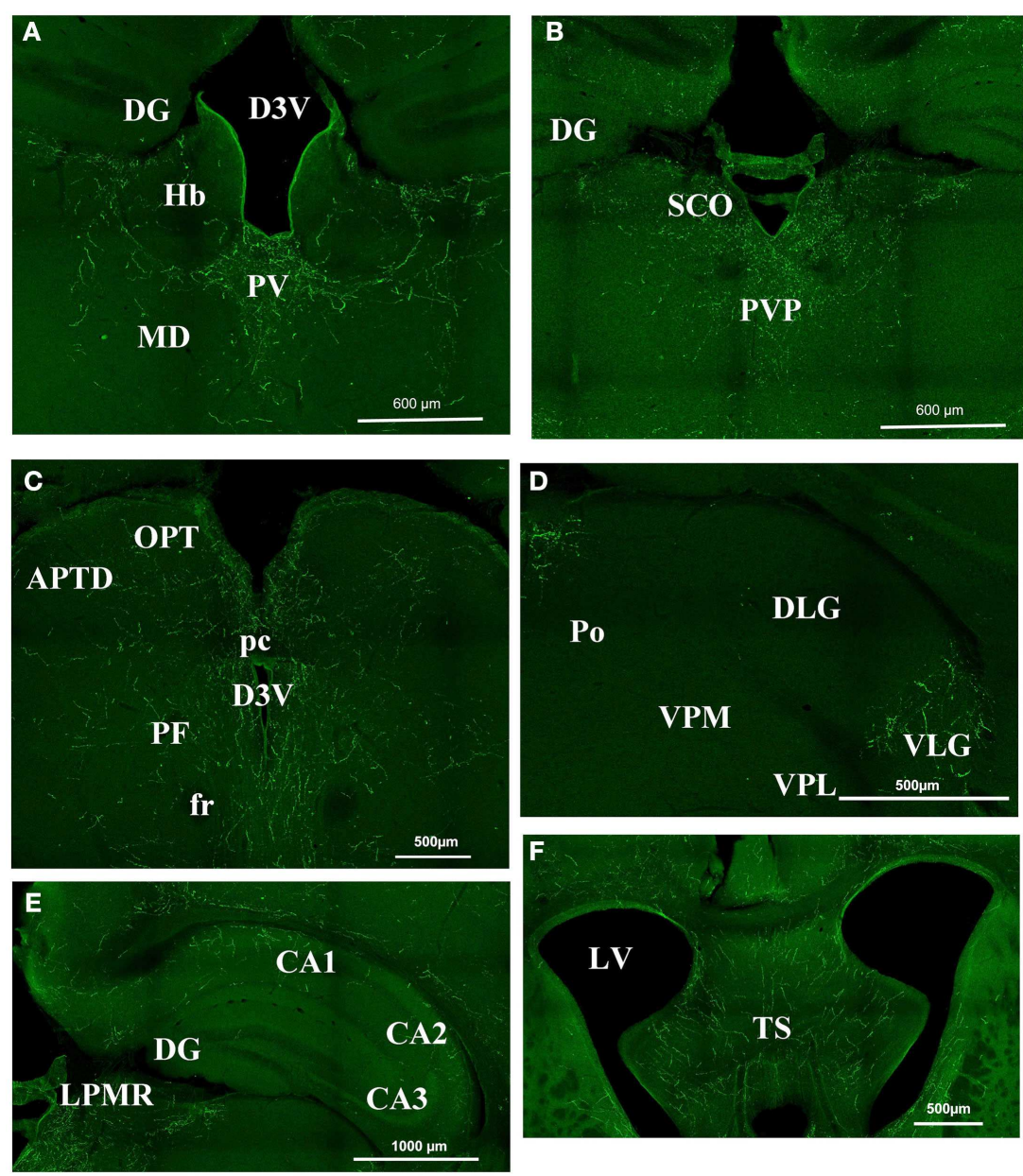

FIGURE 2 | Orexin staining in the thalamus, hippocampus, and septum. (A) Periventricular area Bregma -1.82. Strong staining is visible at the level of the $P V$, while there is no staining in the $\mathrm{DG}$, the $\mathrm{Hb}$, and the MD. (B) Periventricular area at Bregma -2.30. Note the strong staining in the PVP and SCO and still the absence of staining in the DG. (C) Periventricular area at Bregma -2.80 . There is strong staining around the third ventricle, but staining is faint in the OPT and the APTD. (D) Geniculate nucleus. Orexin is present in the VLG but absentin the DLG, the Po, the VPM, and VPL. (E) Hippocampal structures at Bregma -2.3. Note the staining in CA1 CA2 but not in CA3.
(F) Strong staining in the TS. APTD, anterior pretectal nucleus dors.; D3V, dorsal third ventricle; DG, dentate gyrus; DLG, dorsal lateral geniculate; fr, fasciculus retroflexus; $\mathrm{Hb}$, habenular nucleus; LPMR, lat. post. thal. nu. LV, lateral ventricle; MD, medio dorsal thalamus nucleus; OPT, olivary pretectal nucleus; pc, post commissure; PF, para fascicular thalamus nucleus; Po, post. thal. nu.; PV, paraventricular thalamic nucleus; PVP, paraventricular thalamic nucleus post; SCO, sub commissural organ; TS, triangular septal nucleus; VLG, ventral lateral geniculate; VPL, ventro postero lateral thal; VPM, ventro postero med. thal. the olfactory system, as it contains neuromodulatory peptides such as LHRH/GnRH and NPY neurons (Mousley et al., 2006; Kawai et al., 2009). However, both the EBOP and NT project to the POA, which is involved in the regulation of reproductive behavior rather than in food intake behavior, even though these two behaviors are inter-connected indirectly.

Besides, the system involving the NT, it has been possible to trace projections onto the LHRH/GnRH neurons localized in the POA, using Cre-loxP transgenic mice and/or pseudorabies virus infections (Boehm et al., 2005; Yoon et al., 2005). In Figure 1A, we present the projections from the olfactory and hypothalamic regions to the POA. Concerning the olfactory system, most olfactory cortex areas also appear to be connected to the $\mathrm{OB}$ and the OE. As for the hypothalamus connections, most of the hypothalamic nuclei appear to be connected to LHRH/GnRH neurons, among which are VMH, DMH, PVN, LH, and Arc. Therefore, LHRH/GnRH neurons, located in the POA, integrate many afferent signals; amongst which olfactory and hypothalamic inputs to regulate puberty onset, gametogenesis, estrus cycling, and sexual behavior (Gore, 2002) can be found. These connections appear to be bidirectional, since LHRH/GnRH appears to innervate the anterior piriform olfactory cortex (Boehm et al., 2005), indicating the possibility that LHRH/GnRH neurons could in turn modulate both olfactory/pheromonal processing. This has to be considered keeping in mind that both LHRH/GnRH and NPY in axolotl modulate and/or balance both sensitivity to food odorants and pheromones during reproduction periods (Mousley et al., 2006; Kawai et al., 2009).

In the context of olfactory system-hypothalamus connections (Price et al., 1991), the orexin network also has to be considered. 

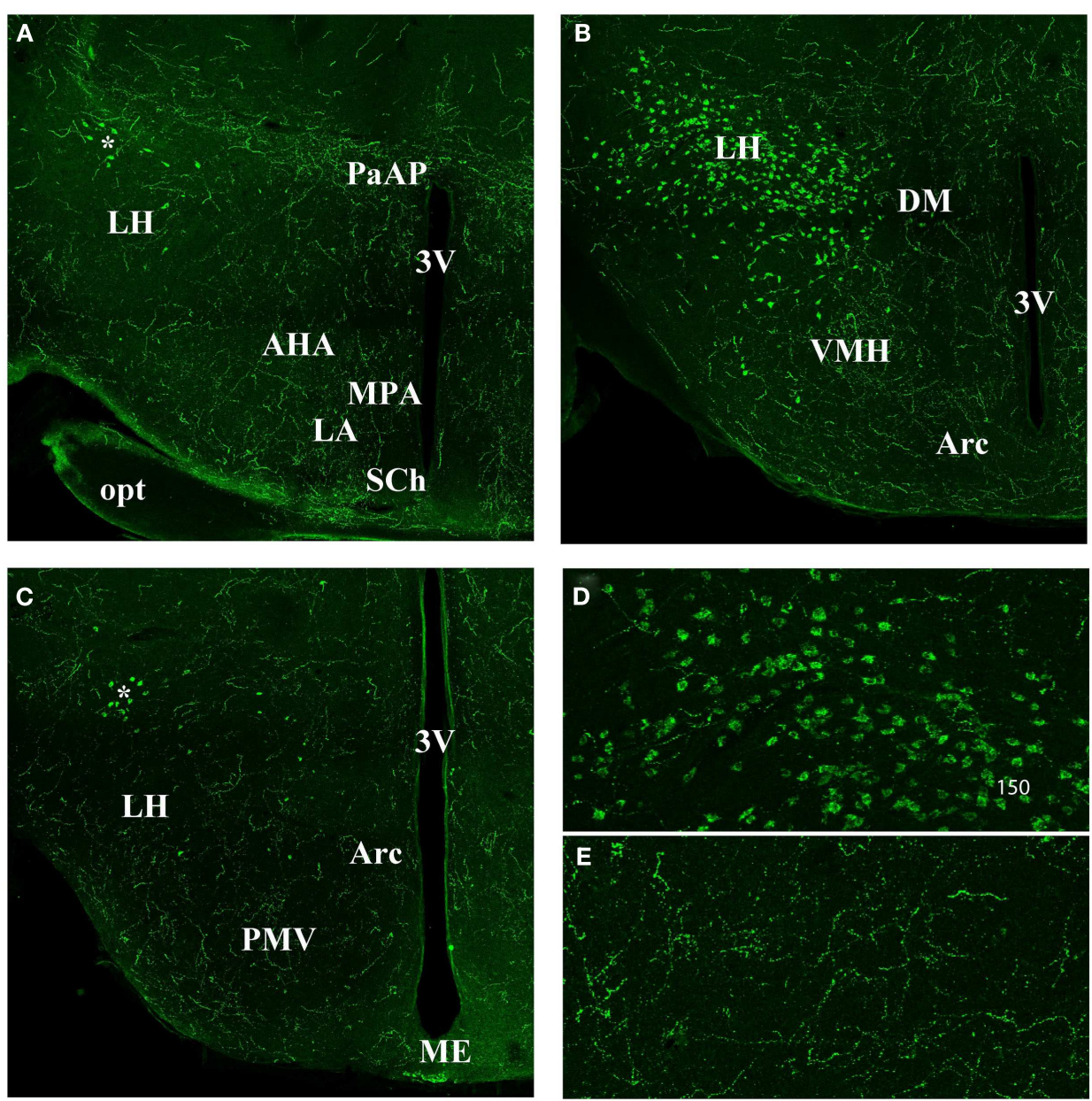

FIGURE 3 | Orexin staining in hypothalamic area (A) anterior part. Note the strong staining in the PaAP, few orexin cell bodies $\left({ }^{*}\right)$ in the anterior $\mathrm{LH}$, and general high staining in the LH, AHA, MPA, LA. Note the absence of staining in the SCh. (B) Orexin staining in the hypothalamus at the level of the orexin neuron population. Note the staining in the DM, VMH, and Arc nucleus. (C) Hypothalamus at the Posterior LH level. Note the few orexin positive neurons $\left({ }^{*}\right)$. Note general staining in the whole hypothalamus including $\mathrm{LH}$,
PMV, Arc, and Me. (D) Magnification of the orexin neuron cell bodies. (E) Magnification of orexin fibers in the hypothalamus. 3V, third ventricle; $A H A$, anterior hypothal. area; Arc, arcuate nucleus; DM, dorso medi hypothal. nu.; LA, lateroant. hypothal. nu.; LH, lateral hypothalamus; MPA, med. preoptic area nu.; ME, med. amyg. nu.; opt, optical nerve. PaAP, pa. anterior parvicell. pt.; PMV, premammill. nu. ventral; $\mathrm{SCh}$, suprachiasmatic nu.; $\mathrm{VMH}$, ventral hypothalamic nu.
Orexins are neuropeptides involved in sleep/waking regulation and food intake behavior (Sakurai et al., 1998, 2010; Aimé et al., 2007; Prud'homme et al., 2009). In rats, orexin neuron cell bodies are located in the perifornical nucleus, and in the dorsal and lateral hypothalamic areas (LHA; Peyron et al., 1998; Nambu et al., 1999). Interestingly, it has been suggested that differentiations in each LHA are involved in the control of specific behavior, with the involvement of the LHA suprafornical region in the control of food intake behavior (Hahn and Swanson, 2010, 2012). High resolution studies of the orexin neuron population in the LH have been carried out (Swanson et al., 2005) showing the extreme complexity of this brain area. In the present study, we focus on the orexin projection fibers - especially in the OB- rather than on the specific segregation of orexin cell bodies within the hypothalamus.

On the one hand, in mice, it has been demonstrated that orexin A neurons receive input from olfactory cortex areas, such as the tenia tecta (Figure 1B; Sakurai et al., 2005). On the other hand, in rats, it has been demonstrated that orexin neurons send projections to the olfactory cortex and OB (Figure 1B; Peyron et al., 1998). The aim of this work was to validate in mice the orexin projection patterns as described in rats (Peyron et al., 1998) with a special focus on the olfactory system.

Our present data show that the main orexin patterns in mice share many features with those in rats (Peyron et al., 1998; Nambu et al., 1999). The comparison of orexin A vs. orexin B staining attests the specificity of orexin A staining (Appendix). Extensive projections were present in nearly all brain areas except the cerebellum, and a high concentration of orexin projections was found in the paraventricular area of the hypothalamus and the thalamus. Amongst the differences to be noted is the absence of staining in the caudate putamen. Otherwise, there was only a small difference between rats and mice in terms of the relative level of the presence of orexin A fibers. 

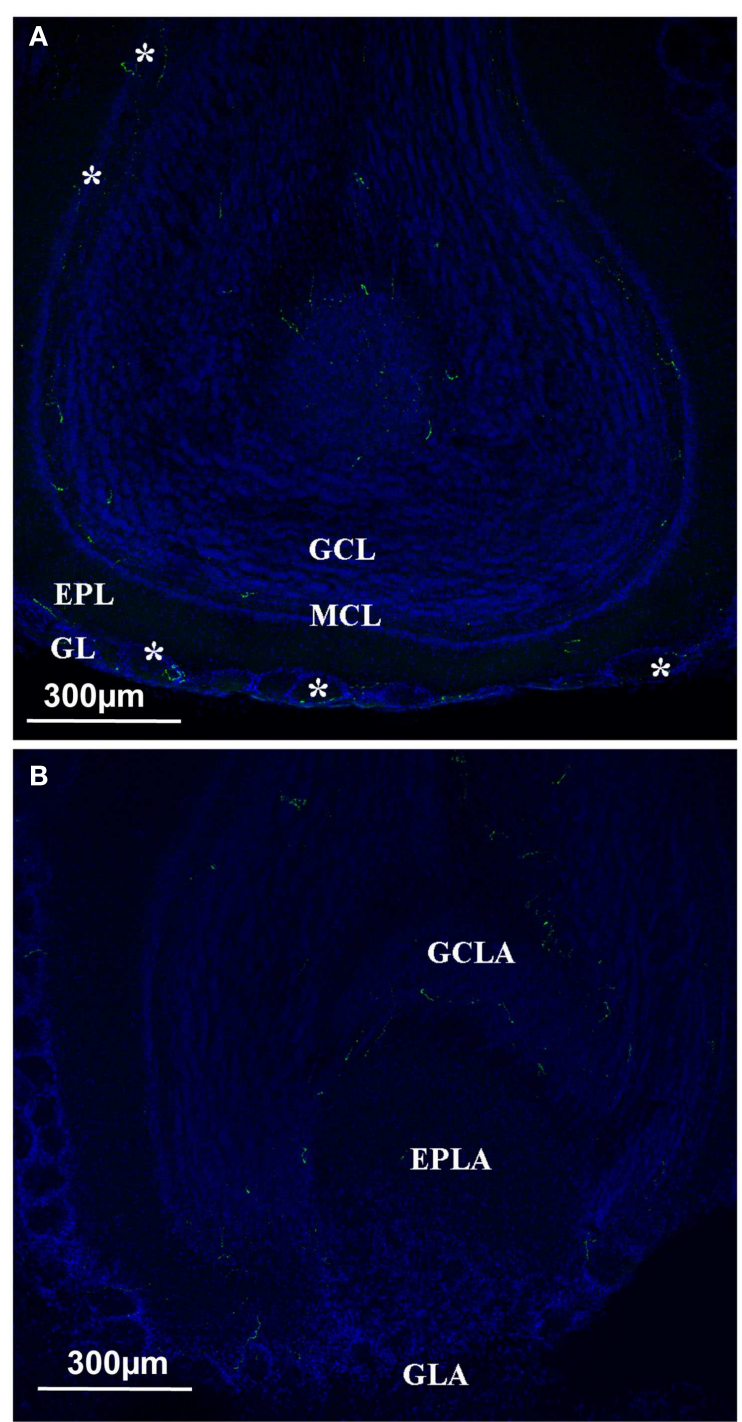

FIGURE 4 | Orexin staining at the level of the olfactory bulb. (A) Main olfactory bulb; the orexin profile (green and white star) could be observed in all the different layers, including the Mitral cell layer arrow). (B) Orexin staining at the level of the Accessory Olfactory bulb. No staining at the level of the AOB except the GCLA. EPL, external plexiform layer; EPLA, external plexiform layer of the accessory olfactory bulb; $\mathrm{GL}$, glomerular layer; $\mathrm{GCL}$, granular cell layer; GCLA, granular cell layer of the accessory olfactory bulb; GLA, glomerular layer of the accessory olfactory bulb; $M C L$, mitral cell layer.

We then investigated in more detail the orexin projections at the level of the OB and olfactory cortex in mice. At the OB level, the density of orexin fibers was noticeably low. Nevertheless, none of the different layers were devoid of orexin fibers, and clear fibers could be seen in the mitral cell layer. At the level of the $\mathrm{OB}$, the pattern of distribution appeared to be different in mice and rats, since in rats few orexin fibers were located in the glomerular and internal granular layers and none in the mitral cell layer (Peyron et al., 1998). To our knowledge, the AOB has not been investigated in rats. In mice, we found that the $\mathrm{AOB}$ was nearly devoid of orexin projections, except for the granular level of the AOB.
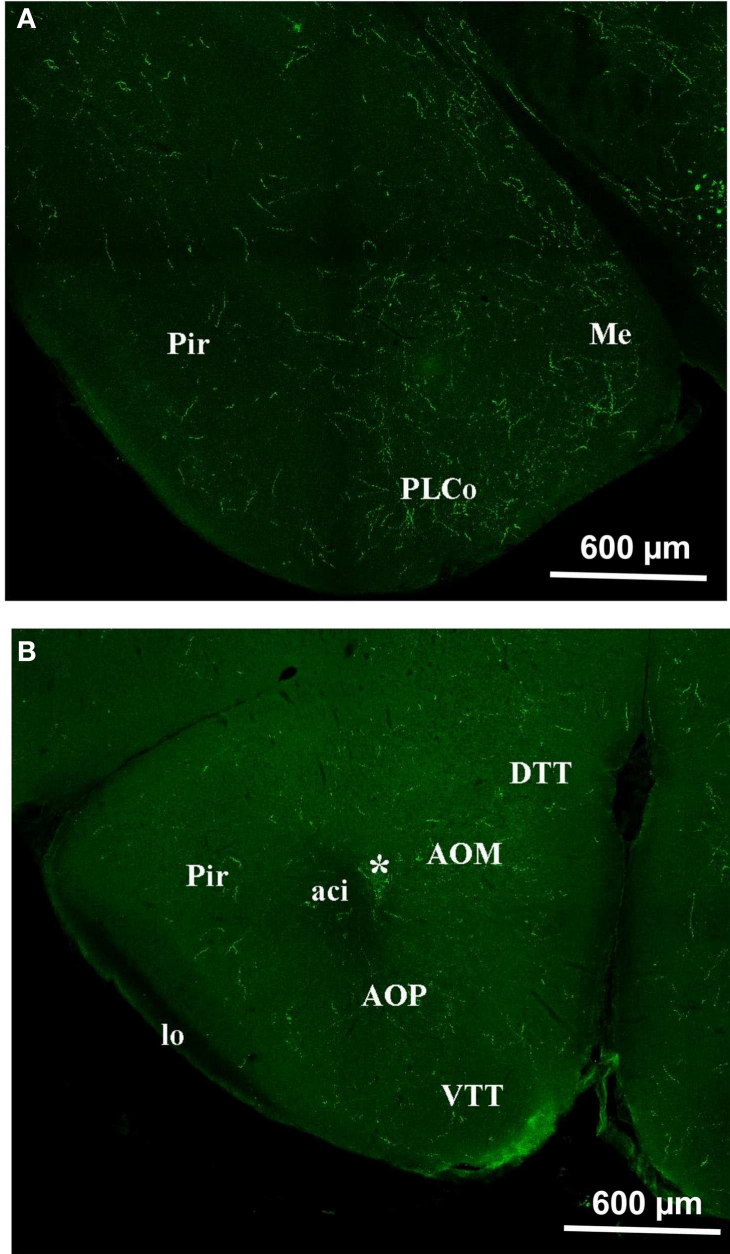

FIGURE 5 | Orexin staining in the olfactory cortex and the Amygdala.

(A) Piriform cortex and amygdala. Note the intense staining in the amygdala and also, though to a lesser extent, in the piriform cortex. (B) Olfactory cortex. Note the staining at the level of the DTT, VTT, AOM, AOP, Pir. *E/OV, Ependy/olfactory ventricle; aci, anterior commissure intrabulbar; $A O M$, anterior olfactory nucleus anterior; $\mathrm{AOP}$, anterior olfactory nucleus posterior; DTT, dorsal tenia tecta; lo: lateral olfactory tract; Me, med amygdala; Pir, piriform cortex; PLCo, postlat cx amygdala nu.; VTT, ventral tenia tecta.

Our results show that the orexin A pattern is similar to those previously described in rats. Orexin fibers on the OB could have two origins. The first origin could be that fibers come from only one cell body population- those that only we and other researchers found to be located in the LH. The second origin could be that fibers, at least in the $\mathrm{OB}$, originate from the olfactory mucosa, since some olfactory receptor neurons are orexin positive (Caillol et al., 2003). However, the second hypothesis seems to be ruled out since the olfactory neurons only project in the glomerular layer, and that we find orexin fibers in all the different layers of the OB. Thus, the projection of $\mathrm{LH}$ orexin neurons to the OB seems to be consensual. However, we cannot claim that synaptic connections of these orexin projections occur at the OB level. In order to establish the precise circuitry between LH and OB, the whole circuitry has to be investigated in detail using a trans-synaptic tracer 

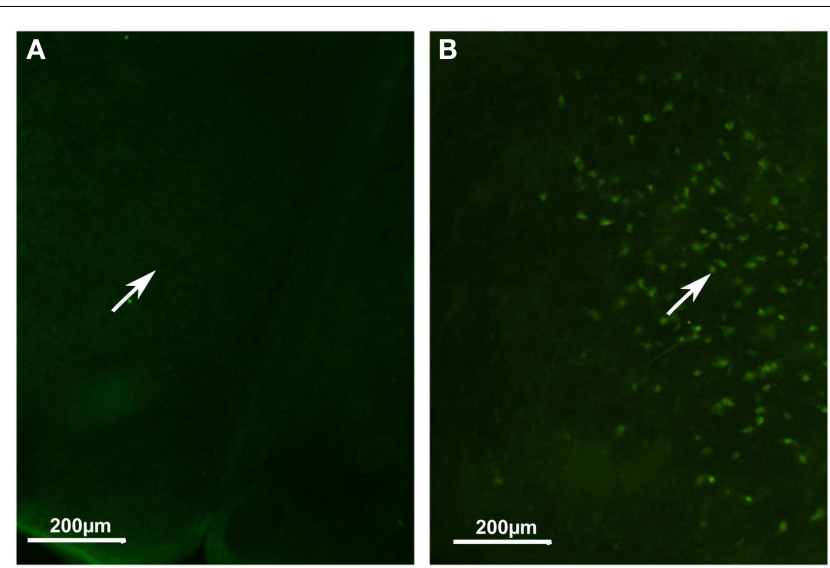

FIGURE 6 | Developmental expression of orexin A in mice. (A) Hypothalamic area at P2. (B) Hypothalamic area at P11. Note orexin cell bodies only in (B) (white arrow).

strategy to demonstrate that $\mathrm{LH}$ orexin neurons constitute a true neuronal circuit between the $\mathrm{OB}$ and the $\mathrm{LH}$.

\section{DEVELOPMENTAL OREXIN PATTERNS}

Considering the developmental expression pattern, orexin has been reported in rats as early as E19 (Van der Pol et al., 2001; Steininger et al., 2004). However, this is highly controversial since other authors have not reported orexinergic neurons before postnatal day 15 (Yamamoto et al., 2000), or at best during the first post-natal week (Stoyanova et al., 2010). Our immunocytochemical results tend to support the late expression of orexin neurons, since we found in mice no evidence of orexin expression at P2, while at P11 instead we showed the presence of orexin neuronal cell bodies. Using qPCR, we observed that significant variations in Ppox mRNA reflect the synthesis of orexin peptides. Indeed, our qPCR results validate our immunohistological results, since at P23 the range of orexin expression is around 500 times lower than that in adults. This supports the idea that the beginning of orexin expression should be between $\mathrm{P} 2-3$ and P11. However, the low level of orexin fibers suggests that the full development of orexin neurons is not complete at $\mathrm{P} 11$ in mice.

\section{REFERENCES}

Aimé, P., Duchamp-Viret, P., Chaput, M. A., Savigner, A., Mahfouz, M., and Julliard, A. K. (2007). Hunger increases and satiation decreases rat olfactory detection performances for a neutral odor. Behav. Brain Res. 179, 258-264.

Apelbaum, A., Perrut, A., and Chaput, M. (2005). Orexin A effects on the olfactory bulb spontaneous activity and odor responsiveness in freely breathing rats. Regul. Pept. 129, 49-61.

Boehm, U., Zou, Z., and Buck, L. B. (2005). Feedback loops link odor and pheromone signaling with reproduction. Cell 123, 683-695.

Cabanac, M., and Duclaux, R. (1973). Olfactory-gustatory alliesthesia and food intake in humans. J. Physiol. 66, 113-135.

Caillol, M., Aïoun, J., Baly, C., Persuy, M. A., and Salesse, R. (2003). Localization of orexins and their receptors in the rat olfactory system: possible modulation of olfactory perception by a neuropeptide synthetized centrally or locally. Brain Res. 960, 48-61.

de Lecea, L., Kilduff, T. S., Peyron, C., Gao, X., Foye, P. E., Danielson, P. E., et al. (1998). The hypocretins: hypothalamus-specific peptides with neuroexcitatory activity. Proc. Natl. Acad. Sci. U.S.A. 6, 322-327.

Doucette, W., Milder, J., and Restrepo, D. (2007). Adrenergic modulation of olfactory bulb circuitry affects

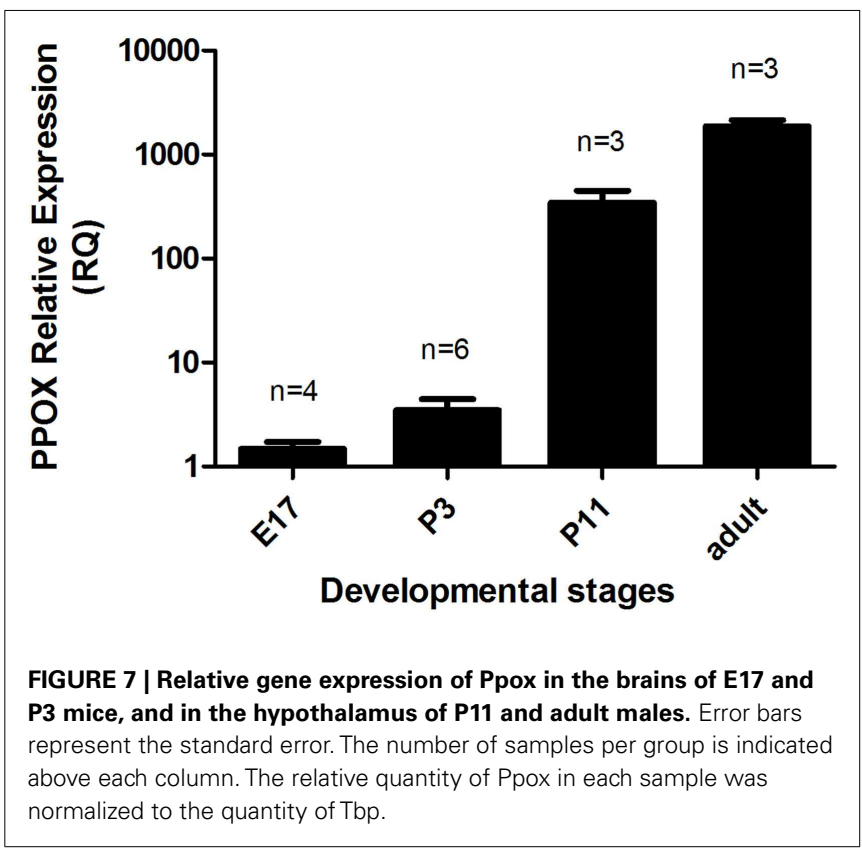

\section{CONCLUSION}

In this study we demonstrate that most of the characteristics of orexin in mice are similar to those reported in rats. Since it has been demonstrated in rats that orexin could modulate olfactory perception depending on the energy balance of the body, this work strongly supports the idea that this is also true in mice. However, trans-synaptic tracing experiments need to be done in order to clearly demonstrate connectivity between the two systems.

\section{ACKNOWLEDGMENTS}

We would like to thanks Prof. P. Bastable and N. Winn for English editing of this paper. This work was supported by Research grant BFU2010-15564 from the Spanish Ministry of Economy and Competitiveness (MINECO) and by INRA (National Institute for Agronomical Research) and the Burgundy Regional Council (Conseil Régional de Bourgogne).

odor discrimination. Learn. Mem. 14, 539-547.

Doucette, W., and Restrepo, D. (2008) Profound context-dependent plasticity of mitral cell responses in olfactory bulb. PLoS Biol. 95, e258. doi:10.1371/journal.pbio.0060258

Duclaux, R., Feisthauer, J., and Cabanac, M. (1973). Effects of a meal on the pleasantness of food and nonfood odors in man. Physiol. Behav. 10, 1029-1033.

Eisthen, H. L., and Polese, G. (2006). "Evolution of vertebrate olfactory subsystems," in Evolution of Nervous Systems, Vol 2: Non-mammalian Vertebrates, ed. J. H. Kaas (Oxford: Academic Press), 355-406.

Elias, C. F., Saper, C. B., Maratos-Flier, E., Tritos, N. A., Lee, C., Kelly, J., et al. (1998). Chemically defined projections linking the mediobasal hypothalamus and the lateral hypothalamic area. J. Comp. Neurol. 402, 442-459.

Fadool, D. A., Tucker, K., and Pedarzani, P. (2011). Mitral cells of the olfactory bulb perform metabolic sensing and are disrupted by obesity at the level of the Kv1.3 ion channel. PLOS ONE 6, e24921. doi:10.1371/journal.pone.0024921

Fletcher, M. L., and Chen, W. R. (2010). Neural correlates of olfactory learning: critical role of centrifugal neuromodulation. Learn. Mem. 17, 561-570.

Friedman, J. M. (2002). The function of leptin in nutrition, weight and physiology. Nutr. Rev. 60, 85-87. 
Fuller, G. N., and Burger, P. C. (1990). Nervus terminalis (cranial nerve zero) in the adult human. $\mathrm{Clin}$. Neuropathol. 9, 279-283.

Garcia-Llanes, F. J., Crespo, C., BlascoIbanez, J. M., Marques-Mari, A. I., and Martinez-Guijarro, F. J. (2003). VIP-containing deep short-axon cells of the olfactory bulb innervate interneurons different from granule cells. Eur. J. Neurosci. 18, 1751-1763.

Gore, A. C. (2002). GnRH: The Master Molecule of Reproduction. Norwell, MA: Kluwer Academic Publisher.

Hahn, J. D., and Swanson, L. W. (2010). Distinct patterns of neuronal inputs and outputs of the juxtaparaventricular and suprafornical regions of the lateral hypothalamic area in the male rat. Brain Res. Rev. 64, 14-103.

Hahn, J. D., and Swanson, L. W. (2012). Connection of the lateral hypothalamic area juxtadorsomedial region in the male rat. J. Comp. Neurol. 520, 1831-1890.

Hass, N., Haub, H., Stevens, R., Breer, H., and Schwarzenbacher, K. (2008). Expression of adiponectin receptor 1 in olfactory mucosa of mice. Cell Tissue Res. 334, 187-197.

Horvath, T. L., and Gao, X. B. (2005). Input organization and plasticity of hypocretin neurons: possible clues to obesity's association with insomnia. Cell Metab. 1, 279-286.

Johnston, J. B. (1914). The nervus terminalis in man and mammals. Anat. Rec. 8, 185-198.

Julliard, A. K., Chaput, M. A., Apelbaum, A., Aimé, P., Mahfouz, M., and Duchamp-Viret, P. (2007). Changes in rat olfactory detection performance induced by orexin and leptin mimicking fasting and satiation. Behav. Brain Res. 183, 123-129.

Kawai, T., Oka, Y., and Eisthen, H. (2009). The role of the terminal nerve and GnRH in olfactory system neuromodulation. Zool. Sci. 26, 669-680.

Matsutani, S., Senba, E., and Tohyama, M. (1988). Neuropeptideand neurotransmitter-related immunoreactivities in the developing rat olfactory bulb. J. Comp. Neurol. 272, 331-342.

Mousley, A., Polese, G., Marks, N., and Eisthen, L. (2006). Terminal nervederived neuropeptide $\mathrm{Y}$ modulates physiological responses in the olfactory epithelium of hungry axolotls. J. Neurosci. 26, 7707-7717.
Nambu, T., Sakurai, T., Mizukami, K., Hosoya, Y., Yanagisawa, M., and Goto, K. (1999). Distribution of orexin neurons in the adult rat brain. Brain Res. 827, 243-260.

Nixon, J. P., and Smale, L. (2007). A comparative analysis of the distribution of immunoreactive orexin A and $B$ in the brains or nocturnal and diurnal rodents. Behav. Brain Funct. $3,28$.

Oka, Y. (1997). "The gonadotropinreleasing hormone (GnRH) neuronal system of fish brain as a model system for the study of peptidergic neuromodulation," in GnRH Neurons: Genes to Behavior, ed. I. S. Parthat and Y. Sakuma (Tokyo: Brain Shuppan Publishers), 245-276

Pager, J. (1978). Ascending olfactory information and centrifugal influx contributing to a nutritional modulation of the rat mitral cell responses. Brain Res. 140, 251-269.

Pager, J., Giachetti, I., Holley, A., and Le Magnen, J. (1972). A selective control of olfactory bulb electrical activity in relation to food deprivation and satiety in rats. Physiol. Behav. 9, 573-579.

Palouzier-Paulignan, B., Lacroix, M. C., Aimé, P., Baly, C., Caillol, M., Congar, P., et al. (2012). Olfaction under metabolic influences. Chem. Senses 37, 769-797.

Peyron, C., Tighe, D. K., van deb Pol, A. N., de Lecea, L., Heller, H. C. Sutcliffe, J. G., et al. (1998). Neurons containing hypocretin (orexin) project to multiple neuronal system. J. Neurosci. 18, 9996-10015.

Pinto, S., Roseberry, A. G., Liu, H. Diano, S., Shanabrough, M., Cai, X., et al. (2004). Rapid rewiring of rcuate nucleus feeding circuits by leptin. Science 304, 110-115.

Price, J. L., Slotnick, B. M., and Revial, M. F. (1991). Olfactory projections to the hypothalamus. J. Comp. Neurol. 306, 447-461.

Prud'homme, M. J., Lacroix, M. C., Badonnel, K., Gougis, S., Baly, C., Salesse, R., et al. (2009). Nutritional status modulates behavioural and olfactory bulb Fos responses to isoamyl acetate or food odour in rats: role of orexin and leptin. Neuroscience 162, 1287-1298.

Royet, J. P., Gervais, R., and Araneda, S. (1983). Effect of local 6-OHDA and 5,6-DHT injections into the rat olfactory bulb on neophobia and learned aversion to a novel food. Behav Brain Res. 10, 297-309.

Sakurai, T., Amemiya, A., Ishii, M., Matsuzaki, I., Chemelli, R. M., Tanaka, H., et al. (1998). Orexins and orexin receptors: a family of hypothalamic neuropeptides and $G$ proteincoupled receptors that regulate feeding behavior. Cell 92, 573-585.

Sakurai, T., and Mieda, M. (2011). Connectomics of orexin-producing neurons: interface of systems of emotion, energy homeostasis and arousal. Trends Pharmacol. Sci. 32, 451-462.

Sakurai, T., Mieda, M., and Tsujino, N. (2010). The orexin system: role in sleep/wake regulation. Ann. N. Y. Acad. Sci. 149-169.

Sakurai, T., Nagata, R., Yamanaka, A., Kawamura, H., Tsujino, N. Muraki, Y., et al. (2005). Input of orexin/hypocretin neurons revealed by a genetically encoded tracer in mice. Neuron 46, 297-308. [Erratum in: Neuron 2005, 46, 837].

Savigner, A., Duchamp-Viret, P., Grosmaitre, X., Chaput, M., Garcia, S. Ma, M., et al. (2009). Modulation of spontaneous and odorant-evoked activity of rat olfactory sensory neurons by two anorectic peptides, insulin and leptin. J. Neurophysiol. 101, 2898-2906.

Steininger, T. L., Kilduff, T. S., Behan M., Benca, R. M., and Landry, C. F. (2004). Comparison of hypocretin/orexin and melaninconcentrating hormone neurons and axonal projections in the embryonic and postnatal rat brain J. Chem. Neuroanat. 27, 165-181.

Stoyanova, I. L., Rutten, W. L. C., and le Feber, J. (2010). Orexin-A and orexin- $\mathrm{B}$ during the postnatal development of the rat brains. Cell. Mol. Neurobiol. 30, 81-89.

Swanson, L. W., Sanchez-Watt, G., and Watt, A. G. (2005). Comparison of melanin-concentrating hormone and hypocretin/orexin mRNA expression patterns in a new parceling scheme of the lateral hypothalamic zone. Neurosci. Lett. 387, 80-84. Tanganelli, S., Fuxe, K., Antonelli, T., O'Connor, W. T., and Ferraro, L. (2001). Cholecystokinin/dopamine/GABA interactions in the nucleus accumbens: biochemical and functional correlates. Peptides 22, 1229-1234.

Van der Pol, A. N., Patrylo, P. R., Ghosh, P. K., and Gao, X. B. (2001). Lateral hypothalamus: early developmental expression and response to hypocretin (orexin). J. Comp. Neurol. 433, 349-363.

Wirsig-Wiechmann, C. R. (1993). Nervus terminalis lesions: I. No Effect on pheromonally induced testosterone surges in the male Hamster. Physiol. Behav. 53, 251-255.

Wirsig-Wiechmann, C. R. (1997). Nervus terminalis lesions: II Enhancement of lordosis induced by tactile stimulation in the hamster. Physiol. Behav. 61, 867-871.

Yamamoto, Y., Ueta, Y., Hara, Y., Serino, R., Nomura, M., Shibuya, I., et al. (2000). Postnatal development of orexin/hypocretin in rats. Brain Res. Mol. Brain Res. 78 , 108-119.

Yeomans, M. R. (2006). Olfactory influences on appetite and satiety in humans. Physiol. Behav. 89, 10-14.

Yoon, H., Enquist, L. W., and Dulac, C. (2005). Olfactory inputs to hypothalamic neurons controlling reproduction and fertility. Cell 123 669-682.

Yoshida, K., McCornack, S., Espana, R. A., Crocker, A., and Scammel, T. E. (2006). Afferent to the orexin neurons of the rat brain. J. Comp. Neurol. $494,845-861$.

Conflict of Interest Statement: The authors declare that the research was conducted in the absence of any commercial or financial relationships that could be construed as a potential conflict of interest.

Received: 17 May 2012; accepted: 06 October 2012; published online: 08 November 2012.

Citation: Gascuel J, Lemoine A Rigault C, Datiche F, Benani A Penicaud $L$ and Lopez-Mascaraque $L$ (2012) Hypothalamus-olfactory system crosstalk: orexin A immunostaining in mice. Front. Neuroanat. 6:44. doi 10.3389/fnana.2012.00044

Copyright (c) 2012 Gascuel, Lemoine, Rigault, Datiche, Benani, Penicaud and Lopez-Mascaraque. This is an openaccess article distributed under the term of the Creative Commons Attribution License, which permits use, distribution and reproduction in other forums, provided the original authors and source are credited and subject to any copyright notices concerning any third-party graphics etc. 


\section{APPENDIX}
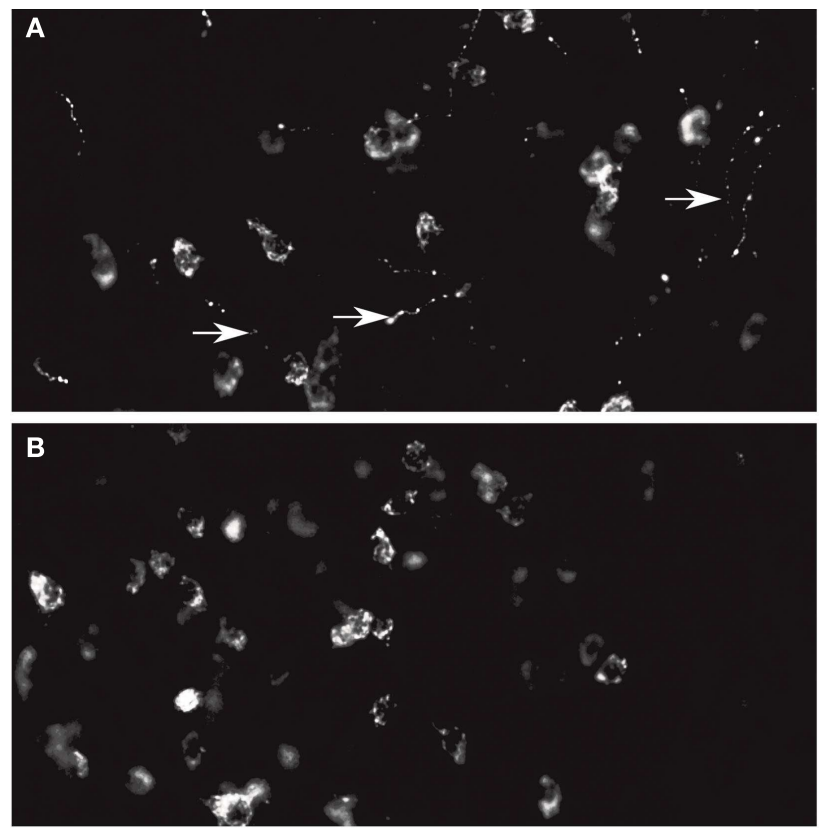

FIGURE A1 | (A) Orexin A staining in the LH. Note the staining at the level of the cell bodies and fibers. (B) Orexin B staining in the LH. Note that the fibers are not stained. In this experiments only primary antibody is different. 